Ruth Grüters, førsteamanuensis, Institutt for lærerutdanning, NTNU, Norge, ruth.gruters@ntnu.no

Knut Ove Eliassen, Institutt for språk og litteratur, NTNU, Norge, knut.eliassen@ntnu.no

\title{
Medieøkologien i SKAM
}

\begin{abstract}
To understand the success of SKAM, the series' innovative use of "social media" must be taken into consideration. The article follows two lines of argument, one diachronic, the other synchronic. The concept of remediation allows for a historical perspective that places the series in a longer tradition of "real time"-fictions and media practices that span from the epistolary novels of the $18^{\text {th }}$ century by way of radio theatre and television serials to the new media of the $21^{\text {st }}$ century. Framing the series within the current media ecology (marked by the connectivity logic of "social media"), the authors analyze how the choice of the blog as the drama's media platform has formed the ways the series succeeded in affecting and mobilizing its audience. Given the long tradition of strong pedagogical premises in the teenager serials of publicly financed Norwegian television, the authors note the absence of any explicit media critical perspectives or didacticism. Nevertheless, the claim is that the media-practices of the series, as well as the actions and discourses of its followers (blogposts, facebook-groups, etc.), generate new insights and knowledge with regards to the series' form, content, and practices.
\end{abstract}

Keywords: Medieøkologi, mediearkeologi, blogg, participatory culture, sosiale medier, remediering

\section{Introduksjon}

Den norskproduserte blogg-serien SKAM har tatt norske, skandinaviske og etter hvert også internasjonale seere med storm. På bloggen til radiokanalen P3 har publikum i mimet real time - gjennom korte videoklipp, meldingstråder og instagram-bilder - kunnet følge livet til jentegjengen Noora, Eva, Chris, Sana og Vilde og deres skolekamerater, og de intriger, forelskelser, drømmer, problemer og, kanskje først og fremst, medier som binder sammen livene til første- og andreklassinger på Hartvig Nissen videregående skole i Oslo.

Seriens uventede, voldsomme og ikke minst brede gjennomslagskraft gjør det i høyeste grad berettiget å spørre hvor den hentet sin sterke appell i fra. Vårt utgangspunkt er at dette ikke - primært - kan forklares verken med dens sujett eller karakterer, men at årsakene er å finne i dens bruk av, både formelt, intrigemessig og performativt, de nye medienes temporalitet og sosialitet - seriens utnyttelse av real time og følgene dette har for dem som er påkoplet slike nettverk. SKAM-seriens relasjon til tidligere mimetiske fiksjoner som har utforsket «sann tid», har vært lite kommentert, og vi vil derfor i det som følger forsøke å innfange hva som er det særlig nye med serien ved å inndra mediearkeologiske perspektiv (Kittler, 1985, Ernst, 2013). Slik vil det analytiske grepet være dobbelt: Dels vil vi vise hvordan serien er innovativ i måten den remedierer eldre innholdsmessige og formmessige mønstre på (Bolter\& Grusin, 2002, Hui Kyong Chun \& Keenan, 2006). Dels vil vi drøfte seriens investering i den aktuelle medieøkologien ved å se på hvordan seriens blogg fungerer som kommunikasjonsplattform, og hvordan egenskapene til messenger, facebook, instagram, etc. anvendes til å drive plottet fremover, skape real time-effekter og etablere en participatory culture.' 
Den følelse av «her og nå» SKAM klarte å vekke, henger i høy grad sammen med at den mobiliserer erfaringer med hvordan den aktuelle mediekonstellasjon skanderer hverdagens rytmer, preger den sosiale temporalitet og etablerer nye affektive økonomier, hvor den konstituerende sosiale handlingen er å «kople seg på»."i Mens serien på den ene siden både performativt og tematisk viser de nye medienes «interpellerende kraft» (telefoner og pc'er varsler om meldinger som påkaller oppmerksomheten), bestemmer rytmene til fellesskapets interaksjon (eller de jevnlige, men, vel å merke, foreløpige sammenbruddene av det samme), og former selvbilder og reaksjonsmønstre (karakterenes virtuelle alter egoer på Facebook og den allment utbredte maniske dokumentasjonsdriften), forteller den på den andre siden også en kjent historie om den nye medierealiteten og om det som modernitetsteoretikere har omtalt med formler som the shock of the new og always already new media (f. eks. Gitelman, 2006). Engasjementet den har vekket, skyldes etter vårt skjønn serieskaper, manusforfatter og regiss $\varnothing r$ Julie Andems suksess med å bruke grensesnitt fra de sosiale mediene til å engasjere publikum og skape en usedvanlig innlevelse i fiksjonen hos følgerne av SKAM-bloggen. iii

Seriens åpenbart oppdragende agenda - unge mennesker foran en ny livsfase - står trygt forankret i en veletablert didaktisk tv-tradisjon i de skandinaviske riksdekkende mediene. Det nye og dets utfordringer og risikoer er en av serieskaper Julie Andems viktigste ressurser, men det pedagogiske perspektivet i SKAMprosjektet omfatter også mer tradisjonelle emner som seksualitet (overgrepet mot Noora), homoseksualitet, etnisitet, foreldrerelasjoner etc. Samtidig kan man bemerke at serien stort sett ignorerer klasseforskjeller, sosiologiske forhold og økonomiske realiteter (penger synes stort sett å være noe man har, og seriens utematiserte klasseperspektiv er storbyens penge- og ressurssterke, utdannede $\varnothing$ vre middelklasse). Serien kan overraskende nok heller ikke sies å være uttalt mediekritisk. I scenen hvor Noora sier passordet sitt høyt i kantinen, brukes ikke dette til et kritisk blikk på mediepraksisen hennes, men som redskap i plottet (Sana logger seg inn på Nooras konto og skriver mail til William).

Andems serie er åpenbart nyskapende, men i et medie- og fiksjonshistorisk perspektiv peker serien - ved dens bruk og tematisering av den nye medieøkologien - uvegerlig på en større kontekst, sanntidsfiksjonens forl $\emptyset$ pere som på ulike vis både utforsket samtidens medier og også ble mediebegivenheter. Eksempler på dette spenner fra det 1700-tallets brevromaner som Samuel Richardsons Clarissa, 1800-tallets avisføljetonger som Dickens The Old Curiosity Shop, 1900-tallets radioteater som Orson Welles' The War of the Worlds til tv-serier som Beverly Hills 90210 og Sex and the City. Ved Clarissas rystende død i den lenge påventede third installment av Clarissa høsten 1748 ringte kirkeklokkene i engelske kirkesogn. Vinteren 1840/41 stod amerikanske lesere på postkaien i Boston og ventet på nytt om Little Nells skjebne i Dickens' føljetong, mens Welles' radiodramatisering av The War of the Worlds utløste panikk i New Jersey høsten 1938. Beverly Hills 90210 og Sex and the City mobiliserte en ny medierealitet (80-tallets $\varnothing$ konomiske og politiske deregulering av tv-mediet og 2000-tallets blogging) for å skape en uhørt identifikasjon med fiktive skikkelser som fremstod som seernes samtidige.

Det er en tautologi å hevde at mediene og deres teknologiske føringer - temporaliteter, økonomier, affekter betinger meningsdannelsen. Enhver oppdatering, om det er på fb, ig eller skam.p3.no, skriver seg inn i et sosialt tolkningsrom som er betinget av det mediet den produseres av. Til forskjell fra det klassiske tv-mediet hvis interaktivitet stort sett begrenser seg til AV/PÅ-knappen og kanalsøkeren, drives de sosiale mediene av aktive brukere som selv deltar på forskjellige måter: affektivt ved hjelp av «likes», opprettelse av lenker og generelt å være pålogget, diskursivt ved å poste kommentarer, mimetisk ved å legge inn bilder og lydsnutter. De er alle påkoplet. I denne deltagerkulturen har de sosiale mediene overtatt telefonens interpellerende funksjon - om ikke en ringetone, så en lyd, en vibrering eller et visuelt ikon; de gjør oppmerksomme på seg selv og på sin eksistens med forskjellige signaler som oppfordrer til respons. Derfor kan fraværet av signaler være et mulig tegn på utelukkelse og avvisning (som når Noora ikke får svar fra William fordi han har mistet telefonen).

Medier, peker Norbert Bolz på, kommer alltid i «forbund» (Bolz, 1993). De reagerer på, tar opp i seg, og supplerer eldre medier. De såkalte sosiale mediene utmerker seg i et historisk perspektiv ved at computeren har visket ut grensesnittene mellom dem. Lyd, bilde og tekst presenteres på samme tekniske plattform, i slående forskjell fra 
det som utgjorde de analoge medienes realitet (Kittler, 1985, 2002). Bloggen blander ulike medier og gjør følgerne oppmerksom på nye postinger. Aktivitetene er ikke kun måter å variere fortellemåten på, de har i kraft av å være mediespesifikke handlinger også følger for plottet. Slik kan en åpen webside avsløre en persons seksuelle legning, en feilsendt melding skape misforståelser, en bloggpost avsløre en kjærlighetsintrige, et fotografi være stigmatiserende, aktiv bruk av telefonen føre til mistanker osv. Fra denne nye medieøkologien henter SKAM sine mimetiske ressurser. Protagonistene, elevene på Hartvig Nissens skole, er til enhver tid opptatt med å sende tekstmeldinger, chatte, ta bilder, surfe på nettet, høre på musikk, etc. Svært sjelden opptrer karakterene alene, for eksempel opptatt med trening, lekselesing eller andre ensomme aktiviteter; utvekslingen av informasjon står slik ikke bare i sentrum for handlingen, de sosiale mediene leverer infrastrukturen til de bånd som holder karakterene sammen. ${ }^{\text {iv }}$

La oss se nærmere på det som skjer på innholdssiden. En gruppe med fem jenter møtes i første videregående og blir tilfeldig en vennegjeng fordi russetiden - den felles sosiale begivenheten som gir retning til kollektivets tid trenger planlegging og gruppesamhold. Hver sesong følger en hovedperson og fokuserer ett bestemt tema eller problem. Emnene spenner over forelskelse, vennskap, homoseksualitet, overgrep, rusmisbruk, kulturmøter og psykisk helse, velkjente temaer fra tv-serier, filmer og litteraturen. Men den bevisste bruken av sosiale medier $\mathrm{i}$ serien gjør noe med den ellers tradisjonelle innholdssiden; dens gjenbruk og resirkulering av gamle temaer i nye formater har den dobbelte effekt av både å presse ny dramatisk energi fra kjente klisjeer, men også å utstille disse som ironiske sitater. Drama- og litteraturhistoriske ekko kan identifiseres i plott og karakterer, hvor de mest åpenbare intertekstuelle referansene omfatter Jane Austen (søstrene Benning og Mr. Darcy, Elinor og Marianne Dashwood), Charlotte Brontë (Jane Eyre og Rochester) og Henrik Ibsen (Nora). Med sine kjærlighetshistorier byr Austen og Brontë på følelsesregistre som spenner fra avmakt, misunnelse og lojalitet til naivitet, kjærlighet og sjalusi, effektive klisjeer om sårbar maskulinitet, og modeller for uavhengige kvinner.

De kanskje tydeligste ekkoene fra Austens Pride and Prejudice er forviklingene og intrigene forbundet med forelskelser og samfunns- og standsmessige utfordringer som i SKAM finner et klart uttrykk i det hierarkiet russefeiringen etablerer på skolen. Den får allerede fra første episode funksjon av å være den sentrale sosiale og rituelle begivenheten i skolens indre liv, og det endemål som bestemmer fellesskapets dynamikk for de tre kommende årene. Slik blir russefeiringen både et narrativt og et sosialt organiseringsprinsipp, et rite-de-passage som det påtagelig knapt nok etableres motforestillinger til i løpet av serien. ${ }^{v}$ Dette innebærer i realiteten et hierarkisk system der førsteklassinger står lavest, mens tredjeklassingene er «adelen» øverst på rangstigen (hvor guttene er like mystisk formuende som Austens mannlige helter). Sett med en førsteklassings blikk er en fest med russegjengen en betydelig og prestisjetung sosial hendelse som derfor også må dokumenteres, gjenfortelles og settes i sirkulasjon - kort sagt, gis realitet - i sosiale medier.

Innholdssiden gir oss i henhold til de ovenstående betraktningene ikke nye, opprivende moment som skulle kunne tilsi seriens popularitet. SKAM-seriens voldsomme oppslutning er neppe å finne i framstillingen av Isaks homofili, men i måten det blir fortalt, dvs. mediert, på. Det begynner med avslutningen av første sesong hvor Noora får låne Isaks mobil og oppdager en åpen gaypornoside. For Noora og Eva faller dermed brikkene på plass. Den nye innsikten gjør at de to jentene kan tolke blikkene Isak kaster på Jonas, som bekreftelse på legning. De siste minuttene i klippet består således kun av blikkutvekslinger mellom Eva og Noora, og Isak og Jonas. Når mistanken slik er bekreftet i serieuniverset, kan den også utfoldes fritt i kommentarfeltet på bloggen. Disse blikkene danner grunnlaget for lesernes entusiastiske kommentarer. Her har leserne lagt igjen 332 kommentarer under den siste bloggposten:

\section{Noen}

Jeg visste isak var HOMO! Endelig

Lol

Jeg visste det hele tiden

Aisha

Omg 


\section{Isak+jonas}

Jeg visste det!! (SKAM 2015)

SKAM tilfører innholdssiden en ny referanseramme når det gjelder å akseptere og godta ung homofili, og temaet «homoseksualitet» blir en god illustrasjon på Andems på mange måter tradisjonelle didaktikk. Men SKAM er ikke en ny opplysningsfilm om hvordan det er å være ung og homofil - den medierer imidlertid temaet på en ny måte (som alle de andre kjente ungdomsfilmtemaene den berører), og bruker medieformatets deltagerimperativ til å skape en uhørt form for nærhet, autentisitet og identifikasjon. Faren for at leserne og seerne skal glemme seriens fiktive karakter er hele tiden til stede, og derfor finnes det pauseklipp midt i sesongen - konstruert stillhet som minner publikummet om at det er fiksjon de ser på og som sådan en egen form for mediepedagogikk. ${ }^{\mathrm{vi}}$

Det som utmerker fenomenet SKAM - altså resepsjonen av og reaksjonen på serien -, er den uvanlige grad publikum inngår og deltar i samme kommunikasjonsunivers som forbinder seriens karakterer. For SKAM er ikke helt til å forstå uten den særlige fandom serien har skapt, som i tråd med de nye medienes muligheter, rekker ut over de nasjonale grensene som tradisjonelt har vært avgrenset nedslagsfeltet for de riksdekkende mediekanalene (Jenkins, 2006b, Atkinson, 2012). Slik har det sågar oppstått en egen skandinavisk fortrolighet i en av de mange og lange diskusjonstrådene på seriens nettside: Skamdinavia. Parallelt med oppdateringen på nettsiden og klippene som vises samlet ved ukeslutt, blir serien diskutert og analysert i ulike grupper på facebook og blant bloggere. vii

Serien skiller seg fra tidligere tv-serier ikke kun ved at hver sesong lar et individ i gruppen være fokaliseringspunkt, både tematisk og mediemessig, men også publikummet tilfører grensesnittet gjennom sin aktive deltakelse i bloggkommentarene både et aktuelt og et pedagogisk aspekt. Resepsjonen av en vanlig dag på SKAM kan beskrives som følger: Datoen på bloggen er den samme som leserens dato. Om det har skjedd en oppdatering, vises klokkeslettet. Er leseren tidlig ute, kan han/hun markere i kommentartråden at hun er fiiiirst eller 1; er leseren sent ute, kan det ta tid å lese gjennom eksempelvis 300 kommentarer før man selv poster noe. Avhengig av spenningsnivået i serien er kommentarene oppgitte, medfølende, rådgivende, og viser liten grad av metabevissthet om seriens fiksjonskarakter. viii $^{2}$

Til tross for at seriens episoder har blitt presentert fortløpende av de statlige tv-kanalene $\mathrm{i}$ alle de tre skandinaviske landene, ${ }^{i x}$ er SKAMs mimetiske grep først og fremst bloggen. Vi vil derfor mene at det er noe misvisende å analysere serien som en tv-føljetong siden dens kraft og appell består i måten den utnytter narrativitet, suspens og identifikasjonskraft som er innebygget i de sosiale medienes brukergrensesnitt. Den iverksetter dermed en annen ordens mimesis ved både tematisk og performativt å trekke veksler på de konsekvenser den nye medierealiteten har for både fiksjonskarakter og publikum. Både seriens karakterer - og plottstrukturen - er preget av at de til enhver tid er «på»; de sosiale mediene utgjør et annet virtuelt rom som fortløpende fordobler den handlingen som utspiller seg i det fysiske fiksjonsrommet. Personene er nesten alltid til stede i to rom, de samtaler med sine venner samtidig som de surfer på nettet, melder, chatter, filmer, etc. Den optiske fordoblingen - vi ser hva Isak skriver mens han sitter sammen med vennene sine, - ledsages av meldingslyder som kunne vært fra ens egen mobil. Selv om den akustisk-mimetiske funksjonen er velkjent fra tidligere filmers telefoner og ringeklokker, forsterkes den i SKAM ved at den speiler publikummets kommunikasjonsmønstre og -handlinger. I en tv-serie som Sherlock (2010- ) brukes riktignok også tv-skjermen til å vise bloggposter og tekstmeldinger, men her for å bringe diskursive opplysninger; i SKAM mimes derimot ungdommenes mediepraksiser, det vil si de mediepraksiser som gir tilskuerne adgang til og delaktighet i serien. Seriens kommunikasjonsformer og deres innhold er hverdagslige og fortrolige - gjennom språkbruk, ordvalg og tilstedeværelse -, men de mobiliserer først og fremst tilskuernes deltagelse.

Dette både pedagogiserende og performativt medrivende - altså ambivalente - aspektet kan spores i opplysende og belærende kommentarer der leserne spekulerer over et tema. Det følgende sitatet fra kommentarfeltet fremstår som eksemplarisk i måten det kombinerer aktualitets- og opplysningsprinsippet på. Videoklippet «lkke døm meg» er datert 3. mai, klokken 13:37. Klippet genererer nesten 600 kommentarer der 
mange er opprørt over at Noora gir bort mailadressen og passordet sitt i kantinen slik at det i prinsippet kan høres av mange. Første kommentaren fra «Lilja» lyder da også: «Nå skal vi lære om nettvett. Ikke del passordet ditt.» Men det er ikke det som skjer. Nooras skjødesløse omgang med passordet brukes ikke til å rette et kritisk blikk på mediebruken; derimot brukes den som plottpådriver i serien. Fansen viderefører heller ikke nettvetttråden, men går over til å diskutere betydningen av Nooras passord "Exper5":

Symbols everywhere

Exper5 $\rightarrow$ (leet) $\rightarrow$ expers $\rightarrow$ (latin) $\rightarrow$ foruten/berøvet/etterlatt (for English speakers: expers is Latin for without/depreived/bereaved) (SKAM 2017a)

Leet

Haha ja. Og digger at klippet ble lagt ut 1337. It's hacking time

1337

Hvorfor er det hacking time?

*ignorant*

1337=LEET (SKAM 2017b)

Lesere som ikke har vært bort i 1337 = LEET, har nå muligheten til å google dette alternative alfabetet som ble brukt av datahackere på 1980-tallet for å kunne kommunisere med hverandre uten at andre skulle forstå det. Etter hvert begynte unge videospillere å bruke det, og det spredde seg gjennom chatting og i ulike online fora. Under dette klippet finnes altså flere kommentarer som ikke beskjeftiger seg med hva som hendte, eller kommer til å skje, fordi Noora var så uforsiktig med å si passordet sitt høyt i kantinen. De retter seg i stedet mot informasjon om formatet: klokkeslettet da klippet ble publisert. Dette viser høy grad av metarefleksivitet om selve mediet, og kommentarene er ikke uten humor:

lol

Kalles ikke å hacke om man allerede har passordet. Det kalles å logge inn :-/ (SKAM 2017c)

Det utradisjonelle og nyskapende ved SKAM ligger ikke i dens pedagogikk som dels preges av velkjente emner, dels undergraves av en distanseløs affektiv mobilisering, men derimot, slik vi har argumentert for her, at serien ved å utforske grensesnittene mellom eldre og nyere medier ikke bare integrerer de unges mediepraksis i selve serien, men også har skapt en refleksiv offentlighet. SKAM-serien kan sies å remediere tv-seriens episodestruktur ved å publisere ukens videoklipp fra bloggen som en hel episode en gang i uken. Men bloggens videoklipp utgjør bare en del av SKAM-universet. På bloggen publiseres det chatte-tråder og instagram-bilder. En leser som følger SKAM via bloggen, får altså flere innholdsbiter enn den som kun ser på ukens TV-episode. Som blogg tilføres serien en avgjørende interaktiv funksjon: lesernes kommentarer. Denne feedback-funksjonen har Andem visst å gjøre bruk av, slik hun også har hatt kontrollgrupper i målgruppen for å sikre at de unges sjargong er i samsvar med det språket som faktisk snakkes i aldersgruppen det handler om. ${ }^{x}$

SKAM er en blogg som overskrider formatet ved å integrere sosiale medier som følgerne bruker på samme måte som karakterene i serien. Ved at korte klipp og meldingstråder legges ut på bloggen, og at alle karakterene også har aktive brukere på instagram, viskes grensen mellom de dramatiske personene og skuespillerne nærmest ut, og publikummet kan leve seg helt og holdent inn i serien. Illusjonen forsterkes av at meldingslydene i de mange chattene i serien er de samme publikummet hører når de chatter, men illusjonen av at fiksjonen viskes ut, blir aldri tematisert på kritisk vis. Enhver form for mediekritikk i Wolfgang Ernsts forstand er fraværende i serien. Derimot forsterkes den felles mediepraksis mellom karakterene og publikummet også gjennom funksjonen som musikken har fått. Låtene legges i en egen SKAM-liste på Spotify, tilgjengelig for fansen, slik at serien bruker samme musikkplattform som publikum. Slik utnyttes mediene til å gi illusjonen av real time: "SKAM» lever i nåtid. Instagram-bildet av Sana etter bombeanslaget i Manchester, 23. mai, kommenteres med: "Dette viser hvor ekte SKAM er" (SKAM 2017d). 
Gitt seriens didaktiske premisser som statsfinansiert ungdomsserie med kvinneperspektiv, kan man overraskes over at dens bruk av litterære sjablonger bidrar til en affektiv mobilisering som truer med å undergrave dens didaktikk. Like fullt må man kunne konstatere at seriens mediepraksiser, både de som utgjør seriens grensesnitt og form, og utenfor i fanskarens blogkommentarer og fb-grupper, tilfører nye innsikter i kjente strukturer på form-, innholds- og praksissiden. Gjennom de nye mediepraksiser SKAM setter i scene, kommer serien til å vise hvordan kjente strukturer på form- og innholdssiden reforhandles i og med nye medie- $\varnothing$ kologier, men vel så viktig, den leverer nye innsikter i hvilke utfordringer et ungt individ som skal lære å administrere seg selv sosialt står overfor i dag. Hva den sier mindre om, er om det fortsatt gir mening å tenke seg et sosialt bånd som ikke er elektronisk mediert, i det minste om ikke annet enn som en kritisk horisont.

\section{Referencer}

Atkinson, S. (2012). The view from the fourth wall window: Crossmedia fictions. In I. Ibrus \& C.A. Scolari (Eds.), Crossmedia Innovations. Texts, Markets, Institutions (pp. 77-92). Frankfurt am Main: Peter Lang GmbH.

Bloustein, G. (2004). Girl-Making: A Cross-Cultural Analysis of the Process of Growing Up Female. Sydney: Bergham Books.

Bolter, J.D., \& Grusin, R. (2002). Remediation. Understanding New Media. Cambridge, Mass.: MIT Press.

Bolz, N. (1993). Am Ende der Gutenberg-Galaxis, München: Wilhelm Fink.

Dijck, J.V. (2015). The Culture of Connectivity. A Critical History of Social Media. New York: Oxford University Press.

Ernst, W. (2013). Digital Memory and the Archive. Minn.: Univ. of Minnesota Press.

Gitelman, L. (2006). Always Already New. Media, History and the Data of Culture. Cambridge, Mass.: MIT Press.

Hui Kyong Chun, W. \& Keenan, T. (Eds.). (2006). New Media, Old Media. A History and Theory Reader. New York: Routledge.

Jenkins, H. (2006a). Convergence Culture: Where Old and New Media Collide. New York: New York University Press.

Jenkins, H. (2006b). Fans, Bloggers, and Gamers: Exploring Participatory Culture. New York: New York University Press.

Jenkins, H., Purushotma, R., Weigel, M., Clinton, K. \& Robison, A. J. (2009). Confronting the Challenges of Participatory Culture: Media Education for the 21st Century. Cambridge, Mass.; The MIT Press.

Kittler, F. A. (1985). Aufschreibesysteme 1800-1900. München: Brinkmann \& Bose.

Kittler, F. A. (1986). Film, Grammofon, Typewriter. München: Brinkmann \& Bose.

Kittler, F. A. (2002). Optische Medien. Berliner Vorlesung 1999. Berlin: Merve Verlag.

SKAM (2015). Retrieved from http://skam.p3.no/2015/12/11/o-come-all-ye-faithful/\#comment-6956

SKAM (2017a). Retrieved from http://skam.p3.no/2017/05/03/ikke-dom-meg/\#comment-115721 
SKAM (2017b). Retrieved from http://skam.p3.no/2017/05/03/ikke-dom-meg/\#comment-115464

SKAM (2017c). Retrieved from http://skam.p3.no/2017/05/03/ikke-dom-meg/\#comment-115375

SKAM (2017d). Retrieved from http://skam.p3.no/2017/05/23/insta-23-mai-kl-1415/\#comment-122482

\footnotetext{
i Vårt begrep om real time er inspirert av Wolfgang Ernsts begrep Medienzeit (Ernst, 2013) Vår forståelse av medienes interpellerende og performative funksjonsmåte står i gjeld til Friedrich Kittlers begrep Aufschreibesysteme (Kittler, 1985, 1986). Endelig hentes begrepet participatory culture fra Henry Jenkins (Jenkins et al, 2009).

ii Det finnes en omfattende litteratur om interaktiv identitetsskapende mediebruk i ungdomskulturen, se f. eks. Bloustein, 2004. For affektive økonomier, se Jenkins, 2006a. For det å være «koplet på», se van Dijck, 2013.

iii Julie Andem har en betydelig merittliste bak seg med serier som gjør bruk av og utforsker de nye mediene. Sara (20082010) følger en fiktiv videoblogg av og om 12-årige jenter, MIA (2010-2012), tre venninner på barneskolenivå som skriver og poster video-snutter på en blog, og Jenter (også om 12-åringer) som fortsatt går (dog ikke lenger regissert av Andem). iv Her utgjør 4. sesong et unntak. Samtidig blir Sanas mediebruk (f.eks. oppretting av en fake-konto på instagram) også et grep for å karakterisere henne som individ.

$\checkmark$ Dette er ikke så rent lite oppsiktsvekkende ettersom det i Norge finnes en lang, ikke minst radikal, tradisjon for å kritisere russefeiringen.

vi Et underfundig brudd på fiksjonen er Isaks øyekast til kameraet på slutten av sesong 2. Det er både et hint om hans rolle $\mathrm{i}$ den følgende sesongen, og en påminnelse til seeren at dette er en fiksjon.

vii Seriens gjennomslagskraft begrenser seg for $\emptyset$ vrig langt fra til Skandinavia, dens appell til russiske, brasilianske eller amerikanske ungdommer vil imidlertid ikke bli berørt av oss.

viii Dette kan naturligvis leses på to måter, begge interessante, nemlig enten som et uttrykk for naivitet, eller som et uttrykk for en vilje til å være med på leken og delta i fiksjonen.

ix | Danmark ble serien kjøpt av DR høsten 2016 og vist på «ungdomskanalen» DR 3 som julekalender av samme år. SVT kjøpte også inn serien i 2016, her ble den imidlertid ikke vist på riksdekkende TV, men derimot lagt ut på WebTV-kanalen SVTPlay i 2016.

x Også reelle episoder fra skolemiljøet i Oslo, for eksempel scenen med flaskeknusingen, er skrevet inn i manus.
} 